\title{
CHARACTERIZATION OF BIOAEROSOLS IN CONTROLLED ENVIRONMENT BROILER HOUSES AT DIFFERENT STAGES OF GROWTH
}

\author{
R. Yasmeen ${ }^{1,2^{*}}$, Z. $\mathrm{Ali}^{2}$, N. Afzal ${ }^{2}$, S. Safdar ${ }^{3}$ and Z. A. Nasir ${ }^{4}$ \\ ${ }^{1}$ Biology Department, Lahore Garrison University, Sector C, DHA Phase VI, Lahore, ${ }^{2}$ Zoology Department, University \\ of the Punjab, Lahore, ${ }^{3}$ University of Veterinary and Animal Sciences (Pattoki) \\ ${ }^{4}$ School of Water, Energy and Environment, Cranfield University, Cranfield, MK43 OAL, UK \\ *Corresponding author's email: raheelasattar44@gmail.com
}

https://doi.org/10.36899/JAPS.2020.1.0010

Published online January 02, 2020

\begin{abstract}
Poultry is critical in fulfilling the protein requirements of the growing populations across the world. However, concerns about the public and environmental health impacts of bioaerosols emissions from intensive poultry facilities are increasing. In the present study, characterization of bioaerosols from air and litter samples was carried out using both culture and non-culture based methods (Flow cytometry). Eighteen controlled environment broiler houses (with approximate 27000 birds) were investigated and categorized into three groups on the basis of age: group I (1-20 days), group II (21-30 days) and group III (31-40 days). The air samples were collected on a polycarbonate filter using a volumetric pump at a height of $1.5 \mathrm{~m}$ both indoor and outdoor of the houses. The litter samples were collected from the floor in sterilized falcon tubes. An increase in the bacterial and fungal count was observed with the age of birds for both indoor air and litter samples. The bacteria found in the litter were reflected in the air but for fungal count, no such association was noticed. Outdoor air samples showed low microbial count as compared to indoor ones. Higher concentrations were recorded for the indoor and outdoor environment with the flow cytometry as compared to culturebased methods.
\end{abstract}

Key words: Poultry houses, Bioaerosols, Culture, Flow cytometry.

\section{INTRODUCTION}

Poultry facilities are important sources of organic dust containing a range of bioaerosols such as bacteria, fungi, pollens, spores, bacterial endotoxins, mycotoxins, peptidoglycans, allergens and plant fibers (Douwes et al., 2003; Vucemilo et al., 2008). The different sources of bioaerosols found in poultry houses are bedding material, feed, litter, feathers and bird's dander (Chang et al., 2001; Chi and Li, 2006). Moreover, cleaning practices, age of buildings, temperature and ventilation rate also exacerbate dust emissions (Banhazi et al., 2008). The emission from these facilities can be a source of various infectious and non-infectious diseases that may have a significant impact on the health of employees as well as nearby communities (Bonlokke et al., 2009; Barberan et al., 2015; Roque et al., 2016). Poultry workers are likely to be exposed to high organic dust, hence, there is an increased likelihood for the prevalence of various respiratory problems like upper respiratory irritation, chronic bronchitis, Organic Dust Toxic Syndrome (ODTS) and asthma-like symptoms among them, due to bioaerosol exposure in these facilities (Donham et al., 2000; Radon et al., 2001; Oppliger et al., 2008; Just et al., 2009). According to Chien et al. (2011), one gram of chicken faeces can release 1000 culturable bacterial colonies and approximately $80 \%$ of these bioaerosols are respirable, so livestock and poultry facilities can be a significant source of exposure to bioaerosols.

The average count of viable airborne bacteria and viable airborne gram-negative bacteria is found to be high in poultry and swine buildings as compared to both insulated and non-insulated dairy houses (Bakutis et al., 2004). Jo and Kang, (2005) also reported higher bioaerosols emissions from swine and poultry houses. However, various factors such as bird density and low ventilation rate are considered the main reasons for enhanced emission of microbes and airborne dust. The microbes can be isolated from airborne dust particles but their role in airborne disease transmission is not fully understood until now, however, the size of airborne dust is a characteristic feature for airborne residence time, dispersion distance and a potential site of deposition in the human respiratory system. Environmental conditions such as temperature and relative humidity also affect the biological survival of microorganisms (Nimmermark et al., 2009; Cambra-Lopez et al., 2010).

In previous studies different air sampling methods (impaction, impingers, filters), and analysis approaches by a range of culture and non-culture methods (epifluorescence microscopy, flow cytometry, fluorescent in situ hybridization, molecular techniques) have been employed to estimate microbes from poultry houses (Chi 
and Li, 2006; Oppliger et al., 2008; Adell et al., 2014). The culture-based method can be useful for providing valuable information on viable particles; however, they are likely to underestimate the microbial load. In fact, culture based methods can underestimate the microbial count by a factor of 10-200 times in comparison to nonculture methods (Chi and Li, 2005).

Studies investigating microbial count from livestock buildings have reported the total bacterial and fungal count, specific genera and different species count both by culture and non-culture methods (Agranovski et al., 2007; Vucemilo et al., 2008; Oppliger et al., 2008; Rinsoz et al., 2008; Adell et al., 2012; De Roy et al., 2012; Liang et al., 2013; Muller and Nebe-von-Caron, 2010; Nonnenmann et al., 2010; Rubbens et al., 2017). A range of bacterial and fungal counts are reported in different studies in poultry houses and other livestock units (Agranovski et al., 2007; Vucemilo et al., 2008; Oppliger et al., 2008; Lonc and Plew, 2011), suggesting spatiotemporal and seasonal variability in emission from poultry houses (Wojcik et al., 2010). One of the studies, conducted in cage house laying hen facility showed the bacterial load in April and December to be $1.02 \times 10^{4}$ $\mathrm{CFU} / \mathrm{m}^{3}$ and $7.72 \times 10^{4} \mathrm{CFU} / \mathrm{m}^{3}$ respectively, while fungal load in September and June was found to be $0.075 \times 10^{4}$ $\mathrm{CFU} / \mathrm{m}^{3}$ and $8.56 \times 10^{4} \mathrm{CFU} / \mathrm{m}^{3}$ respectively (Matkovic et al., 2013).

Among non-culture based analysis methods, flow cytometry (FCM) can advance the characterization of bioaerosols emissions by improving the measurement of total cell count and viability of microorganisms (Berney et al., 2007; Chen and Li, 2007). FCM is widely used in biomedical, microbiology and environmental samples from the aquatic environment as a technique to quantify eukaryotic cell populations, yeast or bacterial cells and phytoplankton (Muller and Nebe-von-Caron, 2010; Wang et al., 2010). Recently, studies are exploring the utility of FCM to identify single cells and fingerprint microbial communities in environmental samples (De Roy et al., 2012; Rubbens et al., 2017). However, the use of FCM to investigate bioaerosols in ambient and indoors environments is limited (Chi and Li, 2006; Liang et al., 2013). There is a need to develop alternative approaches to detect and characterize bioaerosols emissions, in particular, from potential high emission sources such as poultry houses to understand the nature and magnitude of bioaerosols emission from such facilities to develop appropriate control measures and inform regulatory policies.

The poultry sector in Pakistan has shown tremendous progress over the last decade, playing an important role in bridging the gap between the supply and demand for protein with a significant contribution of 1.3 $\%$ in national GDP (Hussain et al., 2015). The sector is also an important source of employment and approximately 1.5 million people are associated with this profession (GOP, 2014). Meanwhile, public health and environmental concerns about emissions (including dust, gases and their bioaerosols) from these facilities are also increasing. However, there is scarce of data on bioaerosols emissions from controlled environment broiler houses from Pakistan. A range of design, use and management factors related to controlled environments broiler houses can greatly impact the bioaerosols emission. These factors are likely to vary across different regions globally due to differences in socio-economic developments, regulatory landscapes, and climatic conditions. Hence there is a need to investigate the levels and nature of bioaerosols emission from intensive poultry farming in different regions of varying socio-economic development stages and climatic conditions in order to inform bioaerosols emission management strategies for such facilities. This study aimed to investigate microbial load with the growing age of birds in controlled environment broiler houses in Lahore, Pakistan. Total airborne bacteria along with differential bacteria (Staphylococcus, Salmonella and gram-negative bacteria) and fungi were determined in poultry houses using culture-dependent methods. In addition, a comparison between culture-dependent methods and cultureindependent methods (FCM) was made.

\section{MATERIALS AND METHODS}

The present study was conducted in 18 controlled environment broiler houses situated in the outskirts of Lahore during Feb-July 2017. The poultry sheds were categorized according to the age of the birds: Group I (1-20 days), Group II (21-30 days) and Group III (31-40 days).

The air sampling by filtration method was done both indoor and outdoor of broiler houses. A volumetric pump sampler was used along with polycarbonate filter (0.22 $\mu \mathrm{m}$ pore size, $47 \mathrm{~mm}$ diameter). The volumetric pump sampler was used with an air flow rate of $36 \mathrm{~L} / \mathrm{min}$ for 15 minutes. The samples were collected at a height of $1.5 \mathrm{~m}$ above the ground and $20-25$ foot away from the exhaust fans inside the poultry house (Figure 1). However, for outdoors, the sampler was placed 15-20 foot away from the side wall of the shed as the placement of sampling apparatus shown in Figure: 1.

The air samples from 18 indoor and outdoor sites were collected and analyzed by either culture-based methods or FCM. Table: 1 lists the detail of downstream analysis (culture-based or FCM) across different poultry houses categories.

After sampling, filters were transferred to $20 \mathrm{ml}$ falcon tubes filled with $10 \mathrm{ml}$ normal saline solution. These along with other sampling equipment were first washed and later on autoclaved at $15 \mathrm{psi}$ pressure, $121^{\circ} \mathrm{C}$ temperature for 30 minutes. Serial dilution for indoor samples was prepared but not for outdoor as a very small 
number of $\mathrm{CFU} / \mathrm{m}^{3}$ were recovered during optimization of the experiment. For serial dilutions, one $\mathrm{ml}$ of stock solution was taken and added in a tube with $9 \mathrm{ml}$ of distilled water and dilutions up to $10^{-7}$ were prepared. Petri plates with Nutrient agar media (CM 003), Sabouraud dextrose agar (CM 0041), Mannitol salt agar (CM 0085, Chapman medium), Eosin methylene blue agar (CM 0069, (modified by Levine), MacConkey agar (M081B), Salmonella-Shigella agar (CM 0099) were prepared and inoculated with $100 \mu \mathrm{l}$ sample from $10^{-3}$, $10^{-5}$. A biosafety cabinet was used for media transfer, inoculation and spreading to reduce the chance of contamination. The plates were incubated at $37^{\circ} \mathrm{C}$ for 24 hours. The plates with Sabouraud dextrose agar were incubated at $37^{\circ} \mathrm{C}$ for $5-7$ days. The bacterial colonies were counted with a colony counter and the results were recorded for each sample. Samples of litter were also collected from each site. One gram of litter sample was used for stock solution and later on, dilutions up to $10^{-10}$ were made. All samples were plated in duplicates and expressed as an average. By using the volume of air sampled (flow rate multiplied with time) and the number of colonies cultured, airborne bacterial count were calculated in terms of colonies counted in a cubic meter of air $\left(\mathrm{CFU} / \mathrm{m}^{3}\right)$. However, for litter samples, the colonies were counted per gram. The different types of colonies that were collected on diverse specific agar media such as Mannitol salt agar (MSA), Eosin methylene blue agar (EMB), MacConkey agar (MCC), and SalmonellaShigella agar (SS) were characterized both morphologically and biochemically (Table 2 and 3). For morphological studies gram staining, capsule staining, shape, and motility tests were performed. However, for biochemical analysis different tests such as catalase, oxidase, urease, IMVIC, coagulase, DNase and Mannitol salt agar tests were performed by the methods of Cappuccino and Sherman, (2005).

Flow cytometry analysis was performed with BD Accuri C6 ${ }^{\circledR}$ cytometer (Becton Dickinson, UK). Total cell concentrations were quantified. Prior to fluorescent staining, the filter samples were vortexed for 2 minutes at a speed of 2 revolutions per minute followed by serial dilutions of samples by using $0.22 \mu \mathrm{m}$ filtered mineral water (Evian, Evian-les-Bains, France). Fluorescent staining and flow cytometry analysis was carried out by the method described in detail by Whitton et al. (2018).

SYBR Green I (SG) $(10,000 \times$ stock $)$ (Invitrogen ${ }^{\mathrm{TM}}$ ) diluted to a working stock concentration of 100× using dimethyl sulfoxide (DMSO) (Fisher Scientific) was used to quantify total cell concentration. A reaction plate of 96 wells was used to prepare the sample before analysis with $2 \mu 1$ Syber Green and $200 \mu 1$ samples. After preparation, the plate was placed in an enclosed microplate thermoshaker (PHMP, GrantBio ${ }^{\mathrm{TM}}$ ) for 13 minutes at $37^{\circ} \mathrm{C}$ at $250 \mathrm{rpm}$ followed by analysis using a BD Accuri C6 flow cytometer (Becton Dickinson, UK). Samples volume of $50 \mu 1$ was analyzed and the data was processed using the Accuri C6 software. The total cell count in air samples was calculated by using the formula:

No of cells per cubic meter of air $=$ Mean number of cells $\times$ Aliquot dilution factor/ Volume of air sampled $/ \mathrm{m}^{3}$.

The data on numbers of total and differential bacteria along with fungi was analyzed SPSS (version 21.00) to compute descriptive statistics.

\section{RESULTS}

The number of colonies on Nutrient agar (NA) was found to be $4.19 \times 10^{4} \pm 4.90 \times 10^{4}, 2.26 \times 10^{5} \pm 1.75 \times 10^{5}$ and $1.15 \times 10^{6} \pm 1.13 \times 10^{6}$ for group I (1-20 days), group II (21-30 days) and group III (31-40 days) respectively (Table: 4). In general, there was an increase in the microbial count with age in all media. In the present study, morphologically different types of colonies were observed on Eosin methylene blue agar (EMB). However, two types were focused and identified as E.coli (green metallic sheen) and Klebsiella (pink, mucoid) colonies. The E.coli (green metallic sheen) was only seen at two sites out of eight and Klebsiella (pink, mucoid) colonies were seen at four out of eight sites. The presence of E.coli and Klebsiella spp. was further confirmed by different morphological and biochemical tests (Table: 5 and 6). The total colony count for both E.coli and Klebsiella spp. was found to be $5.01 \times 10^{2} \pm 7.07 \times 10^{2}$, $2.73 \times 10^{3} \pm 7.71 \times 10^{3}, 7.21 \times 10^{3} \pm 1.02 \times 10^{3}$ for the group I, II and III, respectively (Table: 4). The MacConkey agar (MCC) was used to differentiate fermenter and nonfermenter colonies. No growth was seen at one site while too numerous to count (TNTC) was observed at two sites. However, the microbial count was found to be increasing with the age of birds in group I, II and III and was found to be $6.21 \times 10^{2} \pm 8.67 \times 10^{2}, 2.23 \times 10^{3} \pm 1.51 \times 10^{3}$ and $1.44 \times 10^{4} \pm 1.01 \times 10^{4}$ respectively. It was observed that only three sites showed positive results where Mannitol salt agar (MSA) color turns yellow and golden colored colonies showed the presence of Staphylococcus aureus. The count in different groups was found to be $7.12 \times 10^{3} \pm 9.05 \times 10^{3}, 3.23 \times 10^{4} \pm 6.56 \times 10^{4}$ and $5.66 \times 10^{5} \pm$ $4.99 \times 10^{5}$ for group I, II and III respectively. Moreover, higher bacterial count on MSA agar as compared to all other media showed Staphylococcus aureus existed as the most dominant spp. The Salmonella-Shigella agar (SS) was used to get a total count of Salmonella, Shigella in the air of poultry houses. Two types of colonies were observed as off white colonies with dark centre (Salmonella spp.) and off white (Shigella spp.). The dark centered and off white colonies were counted and on an average of $4.50 \times 10^{2} \pm 1.27 \times 10^{2}, 2.70 \times 10^{2} \pm 3.82 \times 10^{2}$ and $3.78 \times 10^{3} \pm 5.35 \times 10^{3}$ in group 1,2 and 3 respectively 
(Table: 4). The air samples were also analyzed both quantitatively $\left(\mathrm{CFU} / \mathrm{m}^{3}\right)$ and qualitative for fungi using Sabouraud dextrose agar (SDA). The macroscopic identification of fungal species was carried out. Yeast was the most prevailing species; however, unidentified species was recorded as mold. Moreover, mucor, $A$. flavus, A. fumigatus, A. niger were also identified in indoor controlled environment of broiler houses. The overall count was increasing with age of birds and recorded as $2.88 \times 10^{3} \pm 3.06 \times 10^{3}, 4.85 \times 10^{4} \pm 2.87 \times 10^{3}$ and $4.89 \times 10^{4} \pm 3.28 \times 10^{4}$ for the group I, II and III was respectively (Table: 4 ).

Air samples analyzed using FCM showed a higher count compared to Nutrient agar and levels were $9.11 \times 10^{6} \pm 1.10 \times 10^{7}, \quad 1.08 \times 10^{7} \pm 5.64 \times 10^{6} \quad$ and $1.19 \times 10^{7} \pm 9.60 \times 10^{6}$ for group I, II and III respectively (Table: 4).

Litter samples were also analyzed for total and different types of bacteria using various selective agar media. The number of bacteria on NA was TNTC for 3 sites and results from the remaining found to be increasing with each group like $4.63 \times 10^{6} \pm 0.00$, $5.47 \times 10^{8} \pm 7.81 \times 10^{8}$ and $4.73 \times 10^{9} \pm 0.00$ for the group I, II and III respectively. On EMB agar, the count of bacteria was found to be $5.10 \times 10^{6} \pm 0.00,2.18 \times 10^{8} \pm$ 0.00 and TNTC $\times 10^{4} \pm 0.00$ that showed an increase in the count with the age of the birds. There was no growth for one site and dark centred colonies with green metallic sheen (E. coli) and pink mucoid colonies (Klebsiella spp.) was noticed on a few sites. There was a slight increase in bacterial count in group I, II, III as $1.38 \times 10^{7} \pm 1.85 \times 10^{7}$, $2.95 \times 10^{7} \pm 7.97 \times 10^{7}, 8.92 \times 10^{7} \pm 1.26 \times 10^{8}$ and $1.81 \times 10^{8} \pm$ $2.39 \times 10^{8}, 2.30 \times 108 \pm 0.00,3.11 \times 10^{8} \pm 0.00$ respectively in MCC and MSA agar. Furthermore, the bacterial count on MSA compared to other agar media suggested an abundance of gram-positive spp. in these facilities. However, bacterial count on SS agar was decreasing with the age of birds as $1.13 \times 10^{7} \pm 1.59 \times 10^{7}, 3.75 \times 10^{5} \pm$ $1.06 \times 10^{6}$ and $4.80 \times 10^{4} \pm 6.78 \times 10^{4}$ in group I, II and III respectively. The fungal count was found high in group I but a slight decrease was observed in group II and group III as $1.94 \times 10^{7} \pm 2.35 \times 10^{7}, 3.75 \times 10^{5} \pm 1.06 \times 10^{6}$ and $7.75 \times 10^{6} \pm 1.10 \times 10^{7}$ (Table: 5). The most commonly noticed fungi were yeast and in few cases, mold was also found on SDA agar in litter samples. It was noticed that different types of fungi which were observed in air samples were not recorded in the litter samples. This obviously suggests different sources are contributing to fungal load in the air instead of litter. Nonetheless, for bacterial samples, there exists a direct relation between litter and air for SS and MCC agar. It was also observed that if the bacterial load was higher in the litter, then more count was seen in the air samples.

The bacterial count on nutrient agar in the outdoor of group I, group II and group III was found as $4.93 \times 10^{3} \pm 3.50 \times 10^{2}, 4.50 \times 10^{3} \pm 9.93 \times 10^{2}$ and $1.19 \times 10^{4} \pm 1.33 \times 10^{4}$ respectively. There was low bacterial count in the outdoor samples of group II compared to group I and III showed no increase with age of birds in the outdoor environment and outdoor was not a true representative of the indoor environment. The bacterial count on EMB and SS agar for outdoor was not seen for the group I and III while for group II was $7.43 \times 10^{2} \pm 0.00$ and $9.23 \times 10^{2} \pm 2.61 \times 10^{3}$ respectively. MSA was used for staphylococcus aureus and it was seen that out of eight sites, six sites had no growth and only two sites were positive that showed change in color of media for the group I, II and III was NG, $3.60 \times 10^{2} \pm 0.00$ and $7.03 \times 10^{3} \pm 0.00$ respectively. The $0.00 \mathrm{SD}$ was due to one positive sample in each group. The plates for negative results were re-incubated for one more night before discarding as some of the strains of staphylococcus aureus showed delayed results. There was no microbial count on MCC agar for a group I but for group II and III was found to be $1.42 \times 10^{3} \pm 2.04 \times 10^{3}$ and $3.15 \times 10^{3} \pm 0.00$ respectively. The fungal count for outdoor samples was $4.28 \times 10^{2} \pm 3.19 \times 10^{1}, 3.09 \times 10^{3} \pm$ $7.01 \times 10^{2}$ and $1.22 \times 10^{3} \pm 6.37 \times 10^{1}$ (Table: 6 ). The most commonly recorded species of fungi for the outdoor environment was yeast, mold, Mucor, A. flavus, A .niger and particularly on site 3 , the presence of dermatophytes was observed. The FCM results for the outdoor environments of poultry facilities showed an increase in the microbial count for group I-III (Table: 6). The overall count was higher as compared to culture-based technique. 


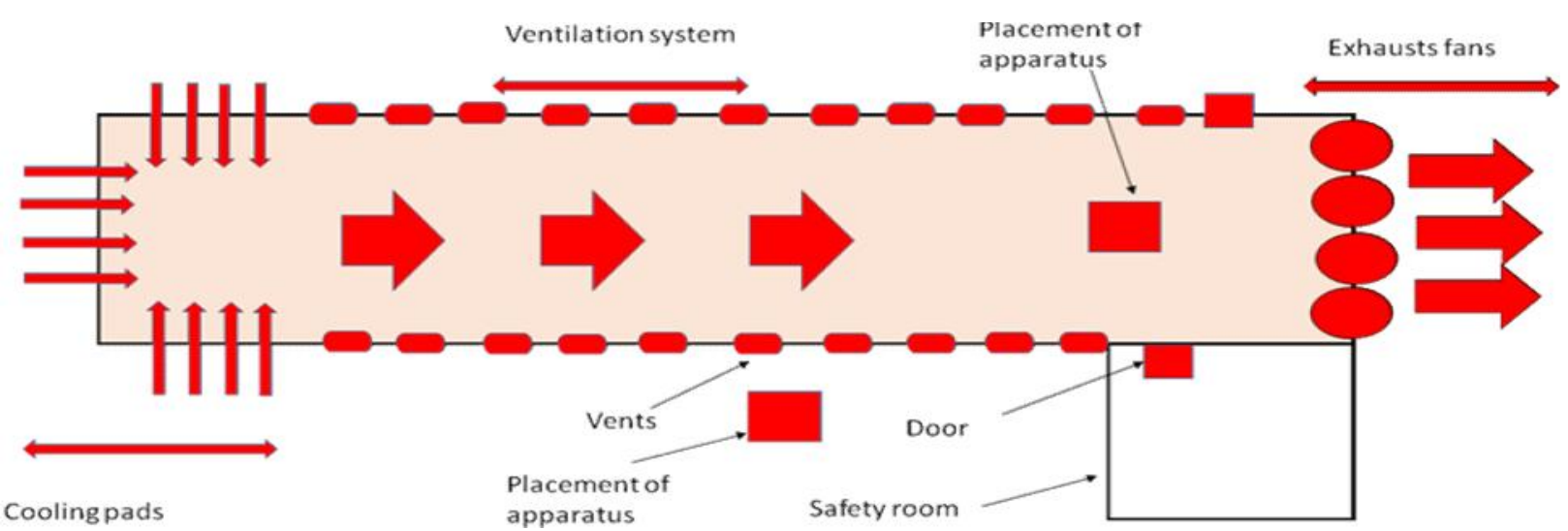

Figure 1. Schematic diagram of poultry houses to show placement of sampling apparatus indoor and outdoor

Table 1. Number of controlled environment broiler houses for both culture and FCM analysis values in parentheses showed total number of visited sites.

\begin{tabular}{lccccc}
\hline \multirow{2}{*}{$\begin{array}{c}\text { Poultry houses } \\
\text { categories }\end{array}$} & \multicolumn{2}{c}{ Indoor } & \multicolumn{3}{c}{ Outdoor } \\
\cline { 2 - 6 } & $\begin{array}{l}\text { No of sheds culture } \\
\text { based analysis (8) }\end{array}$ & $\begin{array}{l}\text { No of shed } \\
\text { analysis (10) }\end{array}$ & $\begin{array}{l}\text { No of } \\
\text { based analysis (8) }\end{array}$ & $\begin{array}{l}\text { sheds culture } \\
\text { No of shed } \\
\text { analysis (10) }\end{array}$ \\
\hline Group I (1-20 days) & 2 & 5 & 2 & 5 \\
Group II (21-30 days) & 4 & 3 & 4 & 3 \\
Group III(31-40 days) & 2 & 2 & 2 & 2 \\
\hline
\end{tabular}

Table 2. Morphological tests for confirmation of Salmonella spp., Shigella spp., E.coli, Klebsiella spp. and Staphylococcus aureus.

\begin{tabular}{|c|c|c|c|c|c|c|c|c|}
\hline Types & $\begin{array}{c}\text { Gram } \\
\text { staining }\end{array}$ & $\begin{array}{l}\text { Capsule } \\
\text { staining }\end{array}$ & Shape & Motility & MaCconkey & SS & EMB & MSA \\
\hline Salmonella & -ve & -ve & Coccobacilli & Motile & $\begin{array}{l}\text { Off white } \\
\text { colonies }\end{array}$ & $\begin{array}{c}\text { Off white } \\
\text { colonies } \\
\text { centrally } \\
\text { black }\end{array}$ & - & - \\
\hline Shigella & $-\mathrm{ve}$ & & Coccobacilli & $\begin{array}{l}\text { Non- } \\
\text { motile }\end{array}$ & $\begin{array}{l}\text { Off white } \\
\text { colonies }\end{array}$ & $\begin{array}{l}\text { Off white } \\
\text { colonies }\end{array}$ & - & - \\
\hline E.coli & -ve & Variable & Rod & Motile & Pink colonies & - & $\begin{array}{c}\text { Green } \\
\text { metallic } \\
\text { sheen }\end{array}$ & - \\
\hline Klebsiella & $-\mathrm{ve}$ & $+\mathrm{ve}$ & Rod & $\begin{array}{l}\text { Non- } \\
\text { motile }\end{array}$ & Pink colonies & - & $\begin{array}{c}\text { Pink } \\
\text { mucoid } \\
\text { colonies }\end{array}$ & - \\
\hline Staphylcoccus & $+\mathrm{ve}$ & $\begin{array}{c}\text { Non- } \\
\text { capsulated }\end{array}$ & Cocci & $\begin{array}{l}\text { Non- } \\
\text { motile }\end{array}$ & - & - & - & $\begin{array}{c}\text { Golden } \\
\text { yellow } \\
\text { colonies, } \\
\text { turns } \\
\text { media } \\
\text { yellow }\end{array}$ \\
\hline
\end{tabular}

MCC: MacConkey agar, SS: Salmonella-Shigella agar, EMB: Eosin methylene blue agar, MSA: Mannitol Salt agar

Table 3. Biochemical test for confirmation of Salmonella spp., Shigella spp., E.coli, Klebsiella

\begin{tabular}{lccccc}
\hline Biochemical tests & Salmonella spp. & Shigella spp. & E.coli & Klebsiella spp. & Staphylococcus aureus \\
\hline Catalase & $+\mathrm{ve}$ & $+\mathrm{ve}$ & $+\mathrm{ve}$ & $+\mathrm{ve}$ & $+\mathrm{ve}$ \\
Oxidase & $-\mathrm{ve}$ & $-\mathrm{ve}$ & $-\mathrm{ve}$ & $-\mathrm{ve}$ & $-\mathrm{ve}$ \\
Urease & $-\mathrm{ve}$ & $-\mathrm{ve}$ & $-\mathrm{ve}$ & $+\mathrm{ve}$ & $+\mathrm{ve}$ \\
\hline
\end{tabular}




\begin{tabular}{lccccc}
\hline Indole production test & $-\mathrm{ve}$ & $-\mathrm{ve}$ & - & $-\mathrm{ve}$ & - \\
Methyl Red test & $-\mathrm{ve}$ & $+\mathrm{ve}$ & $+\mathrm{ve}$ & $-\mathrm{ve}$ & - \\
VogesProskauer's test & $+\mathrm{ve}$ & $-\mathrm{ve}$ & $-\mathrm{ve}$ & $+\mathrm{ve}$ & - \\
Citrate Utilization Test & $+\mathrm{ve}$ & $-\mathrm{ve}$ & $-\mathrm{ve}$ & $+\mathrm{ve}$ & - \\
Coagulase test & - & - & - & - & - \\
DNase & - & - & - & - & $+\mathrm{ve}$ \\
Mannitol salt agar & - & - & - & - & $+\mathrm{ve}$ \\
\hline
\end{tabular}

spp. and Staphylococcus aureus

+ve: positive; -ve: negative 
Table 4. Summary of indoors airborne microbial counts with different types of agar and FCM across three poultry houses categories.

\begin{tabular}{lccc}
\hline & Group I (1-20 days) & Group II (21-30 days) & Group III (31-40 days) \\
\cline { 2 - 4 } Indoor & Avg \pm SD $\left(\mathbf{C F U} / \mathbf{m}^{\mathbf{3}}\right)$ & Avg \pm SD $\left(\mathbf{C F U} / \mathbf{m}^{\mathbf{3}}\right)$ & Avg \pm SD $\left(\mathbf{C F U} / \mathbf{m}^{\mathbf{3}}\right)$ \\
\hline NA & $4.19 \times 10^{4} \pm 4.90 \times 10^{4}$ & $2.26 \times 10^{5} \pm 1.75 \times 10^{5}$ & $1.15 \times 10^{6} \pm 1.13 \times 10^{6}$ \\
EMB & $5.01 \times 10^{2} \pm 7.07 \times 10^{2}$ & $2.73 \times 10^{3} \pm 7.71 \times 10^{3}$ & $7.21 \times 10^{3} \pm 1.02 \times 10^{3}$ \\
MCC & $6.21 \times 10^{2} \pm 8.67 \times 10^{2}$ & $2.23 \times 10^{3} \pm 1.51 \times 10^{3}$ & $1.44 \times 10^{4} \pm 1.01 \times 10^{4}$ \\
MSA & $7.12 \times 10^{3} \pm 9.05 \times 10^{3}$ & $3.23 \times 10^{4} \pm 6.56 \times 10^{4}$ & $5.66 \times 10^{5} \pm 4.99 \times 10^{4}$ \\
SS & $4.50 \times 10^{2} \pm 1.27 \times 10^{2}$ & $2.70 \times 10^{2} \pm 3.82 \times 10^{2}$ & $3.78 \times 10^{3} \pm 5.35 \times 10^{3}$ \\
SDA & $2.88 \times 10^{3} \pm 3.06 \times 10^{3}$ & $4.85 \times 10^{4} \pm 2.87 \times 10^{3}$ & $4.89 \times 10^{4} \pm 3.28 \times 10^{4}$ \\
FCM & $9.11 \times 10^{6} \pm 1.10 \times 10^{7}$ & $1.08 \times 10^{7} \pm 5.64 \times 10^{6}$ & $1.19 \times 10^{7} \pm 9.60 \times 10^{6}$
\end{tabular}

NA: Nutrient agar, EMB: Eosin methylene blue agar, MCC: MacConkey agar, MSA: Mannitol Salt agar, SS: Salmonella-Shigella agar, SDA: Sabouraud dextrose agar, FCM: Flow cytometry, SD: Standard deviation, AVG: Average

Table 5. Summary of microbial counts with different types of agar in litter across three poultry houses categories.

\begin{tabular}{lccc}
\hline \multirow{2}{*}{ Litter } & Group I (1-20 days) & Group II (21-30 days) & Group III (31-40 days) \\
\cline { 2 - 4 } & Avg \pm SD (CFU/g) & Avg \pm SD (CFU/g) & Avg \pm SD (CFU/g) \\
\hline NA & $4.63 \times 10^{6} \pm 0.00$ & $5.47 \times 10^{8} \pm 7.81 \times 10^{8}$ & $4.73 \times 10^{9} \pm 0.00$ \\
EMB & $5.10 \times 10^{6} \pm 0.00$ & $2.18 \times 10^{8} \pm 0.00$ & TNTC $\times 10^{4} \pm 0.00$ \\
MCC & $1.38 \times 10^{7} \pm 1.85 \times 10^{7}$ & $2.95 \times 10^{7} \pm 7.97 \times 10^{7}$ & $8.92 \times 10^{7} \pm 1.26 \times 10^{8}$ \\
MSA & $1.81 \times 10^{8} \pm 2.39 \times 10^{8}$ & $2.30 \times 10^{8} \pm 0.00$ & $3.11 \times 10^{8} \pm 0.00$ \\
SS & $1.13 \times 10^{7} \pm 1.59 \times 10^{7}$ & $3.75 \times 10^{5} \pm 1.06 \times 10^{6}$ & $4.80 \times 10^{4} \pm 6.78 \times 10^{4}$ \\
SDA & $1.94 \times 10^{7} \pm 2.35 \times 10^{7}$ & $4.46 \times 10^{7} \pm 9.56 \times 10^{7}$ & $7.75 \times 10^{6} \pm 1.10 \times 10^{7}$ \\
\hline
\end{tabular}

NA: Nutrient agar, EMB: Eosin methylene blue agar, MCC: MacConkey agar, MSA: Mannitol Salt agar, SS: Salmonella-Shigella agar, SDA: Sabouraud dextrose agar, FCM: Flow cytometry, SD: Standard deviation, AVG: Average

Table 6. Summary of outdoors microbial counts with different types of agar and FCM across three poultry houses categories.

\begin{tabular}{lccc}
\hline Outdoor & Group I (1-20 days) & Group II (21-30 days) & Group III (31-40 days) \\
\cline { 2 - 4 } & $\mathbf{A V G} \pm \mathbf{S D}\left(\mathbf{C F U} / \mathbf{m}^{3}\right)$ & AVG \pm SD $\left(\mathbf{C F U} / \mathbf{m}^{3}\right)$ & $\mathbf{A V G} \pm \mathbf{S D}\left(\mathbf{C F U} / \mathbf{m}^{3}\right)$ \\
\hline NA & $4.93 \times 10^{3} \pm 3.50 \times 10^{2}$ & $4.50 \times 10^{3} \pm 9.93 \times 10^{2}$ & $1.19 \times 10^{4} \pm 1.33 \times 10^{4}$ \\
EMB & NG & $7.43 \times 10^{2} \pm 0.00$ & $\mathrm{NG}$ \\
MCC & NG & $1.42 \times 10^{3} \pm 2.04 \times 10^{3}$ & $3.15 \times 10^{3} \pm 0.00$ \\
MSA & NG & $3.60 \times 10^{2} \pm 0.00$ & $7.03 \times 10^{3} \pm 0.00$ \\
SS & NG & $9.23 \times 10^{2} \pm 2.61 \times 10^{3}$ & NG \\
SDA & $4.28 \times 10^{2} \pm 3.19 \times 10^{1}$ & $3.09 \times 10^{3} \pm 7.01 \times 10^{2}$ & $1.22 \times 10^{3} \pm 6.37 \times 10^{1}$ \\
FCM & $4.08 \times 10^{5} \pm 1.18 \times 10^{7}$ & $1.27 \times 10^{6} \pm 1.55 \times 10^{6}$ & $5.65 \times 10^{6} \pm 4.33 \times 10^{5}$ \\
\hline
\end{tabular}

NA: Nutrient agar, EMB: Eosin methylene blue agar, MCC: MacConkey agar, MSA: Mannitol Salt agar, SS: Salmonella-Shigella agar, SDA: Sabouraud dextrose agar, FCM: Flow cytometry, SD: Standard deviation, AVG: Average

\section{DISCUSSION}

The average range of indoors total bacteria and fungi in the existing study was found to be $4.19 \times 10^{4}$ to $1.15 \times 10^{6}$ and $2.88 \times 10^{3}$ to $4.89 \times 10^{4}$ respectively. The microbial count was increased with the age of birds likely due to an increase in the biomass of the birds and this was in agreement with findings of Agranovski et al. (2007), who described the range of bacteria as $1.12 \times 10^{5}$ to 6.38 $\mathrm{x} 10^{6} \mathrm{CFU} / \mathrm{m}^{3}$ with mean count of $2.89 \times 10^{5} \mathrm{CFU} / \mathrm{m}^{3}$ and range of fungi as $4.4 \times 10^{3}$ to $6.2 \times 10^{5} \mathrm{CFU} / \mathrm{m}^{3}$ with a mean count of $3.32 \times 10^{4} \mathrm{CFU} / \mathrm{m}^{3}$ in these facilities. According to the authors, the bioaerosols emission increased with the age of the birds and more count was recorded at the $4-5^{\text {th }}$ week of growth. Agranovski et al. (2007) also reported gram-positive as the most prevailing bacteria in these facilities which were also observed in the present study. The present study is also in agreement with Lonc and Plewa, (2011), who reported that poultry facilities contributed a considerable amount of bioaerosols emissions. The presence of bacteria (Staphylococcus aureus, E.coli, Klebsiella spp., Salmonella spp., Shigella spp.) and fungi (Yeast, Mucor, A. flavus, A. fumigatus, A. niger, dermatophytes) in both air and litter samples was also reported by Soliman et al. (2009). However, in the existing study, different types of 
fungi that were observed in the air samples were not recorded in the litter samples. This suggests different sources are contributing to fungal load in the air such as feed, bird's feather, excreta and skin dandruff (Gigli et al., 2005; Viegas et al., 2012). Moreover, it was also reported by De Lucca, (2007), that fungal species that were not recorded in litter samples may be due to excessive use of antibacterial medicines that suppress the growth of fungal species. One reason for lesser fungal load in the litter may be the process of microbial mineralization by which noxious gases are produced and may affect the fungal growth.

According to many studies (Agranovski et al., 2007; Vucemilo et al., 2008; Lonc and Plewa, 2011), the range of bacterial and fungal count found as $10^{3}$ to $10^{10}$ $\mathrm{CFU} / \mathrm{m}^{3}$ and $2.5 \times 10^{1}$ to $4.9 \times 10^{6} \mathrm{CFU} / \mathrm{m}^{3}$ respectively in the air of these facilities. However, Skora et al. (2016), reported bacterial and fungal load in settled dust as $3.2 \mathrm{x}$ $10^{9} \mathrm{CFU} / \mathrm{g}$ and $1.2 \times 10^{6} \mathrm{CFU} / \mathrm{g}$ respectively. The higher microbial count and more exposure of workers to bioaerosols was reported with increasing age of birds (Jerez et al., 2014).

In the present study, Staphylococcus acts as a dominant genera and a higher count was noticed in the litter as well as in the air samples of the controlled environment broiler houses; in line with reported higher prevalence of Staphylococcus by Oppliger et al. (2008) and Just et al. (2011). According to Schulz et al. (2004), Staphylococci bacteria act as useful indicators for bioaerosols emissions in poultry facilities due to their characteristic features such as high survival rate, non spore forming ability and use of air as disease transmitter medium.

The next dominant spp. in the present study was E.coli and Klebsiella (collected on EMB agar) and Chinivasagam et al. (2009), also reported $20 \mathrm{CFU} / \mathrm{g}$ of E.coli in litter and dust samples and $5 \mathrm{CFU} / \mathrm{m}^{3}$ in the air by the culture-dependent method. The presence of bacteria and fungi in these facilities is natural as the facilities provide optimal environmental conditions that help to promote the growth of microbes (Vucemilo et al., 2008; Romanowska-Słomka and Mirosławski, 2009; Nonnenmann et al., 2010). However, it is vital to understand the contribution of emission from such facilities in relation to natural background levels in order to characterize the magnitude of bioaerosols exposure to workers and the general public. In the current study, a high mortality rate of birds was recorded at one site. It was informed by management that the building was not properly disinfected before getting a new flock from the last few turns. However, higher levels of microbial contamination, like the presence of the dermatophytes both indoor and outdoor air of that particular site confirmed that the condition of the building acts as a critical factor for the contribution of contaminants. According to Lonc and Plewa, (2011), the microbial load in these facilities showed fluctuation and Donderski et al. (2005), reported that the bioaerosols count even showed high variations within few minutes and concentration of emissions alter with the activity of birds and change of microclimate.

In the current study higher microbial counts were recorded with FCM as compared to culture-based method and this is in line with other studies (Chen and $\mathrm{Li}$, 2007; Chi and Li, 2005; Chi and Li, 2006; Chi and Li, 2007; Rinsoz et al., 2008; Muller and Nebe-von-Caron 2010; Nonnenmann et al., 2010; De Roy et al., 2012; Liang et al., 2013; Rubbens et al., 2017). This demonstrates the shortcomings of the culture-based method to characterize the extent of exposure to bioaerosol emissions. There are different limitations in culture-based methods as the methods gave an underestimation of the microbial load, are laborious and time-consuming (days-week) (Yoo et al., 2017). Furthermore, these culture-based methods may not recover all viable bioaerosols due to specific incubation temperature and cultivation media used (Peccia and Hernandez, 2006; Rinsoz et al., 2008). In the existing study, a low microbial count was seen in the outdoor of these facilities, moreover, outdoor fungal species were found different as compared to indoor. The similar results for fungus were also reported for both indoor and outdoor of these facilities by Viegas et al. (2012). The results were also comparable to Crook et al. (2008) and Lonc and Plew, (2011), who reported low microbial count in the outdoor as compared to the indoor of these facilities.

Conclusion: The present study showed that bacterial and fungal counts in air and litter samples increased with the age of birds. Moreover, there was a direct relation of microbial counts in litter samples with air samples. There was higher bacterial count noticed for gram-positive bacteria (Staphylococcus aureus) on MSA agar compared to bacterial count on all other media. Different factors such as the age of birds along with management practices play a crucial role in the bioaerosols emissions. The bioaerosols levels in the outdoor environment were lower than those in the indoor environment. Higher concentrations were found with FCM in comparison to culture-based methods which clearly highlight the limitations of culture-based methods to provide information on the nature and magnitude of bioaerosols emissions. The study will act as baseline data for bioaerosols emissions from controlled environment broiler facilities in Pakistan. It will also provide an evidence base for the regulators and farmers to develop policies and mitigation strategies to improve the environment for the birds and the health of poultry workers.

Acknowledgments: We are extremely thankful to Prof. Dr. Aftab Ahmad Anjum, Dr. Asad and Dr. Imran Najeeb of Microbiology Department, University of Veterinary 
and Animal Sciences for their support at every step of our work.

\section{REFERENCES}

Adell, E., S. Calvet, A.G. Torres, and M. Cambra-López (2012). Particulate matter concentrations and emissions in rabbit farms. World Rabbit Sci. 20(1): 1-12.

Adell, E., V. Moset, Y. Zhao, A. Jiménez-Belenguer, A. Cerisuelo, and M. Cambra-López (2014). Comparative performance of three sampling techniques to detect airborne Salmonella species in poultry farms. Ann.Agric. Environ. Med. 21(1).

Agranovski, V., T. Reponen, and Z.D. Ristovski (2007). Survey of bioaerosol emissions from Australian poultry buildings. Europ. Aerosol Conference. Salzburg, Abstract (28).

Bakutis, B., E. Monstviliene, and G. Januskeviciene (2004). Analyses of airborne contamination with bacteria, endotoxins and dust in livestock barns and poultry houses. Acta. Vet. Brno. 73(2): 283289.

Banhazi, T.M., J. Seedorf, M. Laffrique, and D.L. Rutley (2008). Identification of the risk factors for high airborne particle concentrations in broiler buildings using statistical modelling. Biosys. Eng. 101(1): 100-110.

Barberan, A., J. Ladau, J.W. Leff, K.S. Pollard, H.L. Menninger, R.R. Dunn, and N. Fierer (2015). Continental-scale distributions of dustassociated bacteria and fungi. Proc. Natl Acad. Sci. 201420815.

Berney, M., F. Hammes, F. Bosshard, H.U. Weilenmann, and T. Egli (2007).Assessment and interpretation of bacterial viability by using the LIVE/DEAD BacLight Kit in combination with flow cytometry. Appl. Environ. Microbiol.73(10): 3283-3290.

Bonlokke, J.H., A. Meriaux, C. Duchaine, S. Godbout, and Y. Cormier (2009). Seasonal variations in work-related health effects in swine farm workers. Ann. Agric. Environ. Med. 16(1): 4352 .

Cambra-López, M., A.J. Aarnink, Y. Zhao, S. Calvet, and A.G. Torres (2010). Airborne particulate matter from livestock production systems: A review of an air pollution problem. Environ. Poll. 158(1): $1-17$.

Cappuccino, J. G., and N. Sherman (2005). Microbiology: a laboratory manual ( $p$. 507). San Francisco: Pearson/Benjamin Cummings.

Chang, C.W., H. Chung, C.F. Huang, and H.J.J. Su (2001). Exposure of workers to airborne microorganisms in open-air swine houses. Appl. Environ. Microbiol. 67(1): 155-161.

Chen, P.S., and C.S. Li (2007). Real-time monitoring for bioaerosols-flow cytometry. Analyst.132(1): 14-16.

Chi, M.C., and C.S Li (2005). Fluorochrome and fluorescent in situ hybridization to monitor bioaerosols in swine buildings.Aerosol Sci. Technol.39(11): 1101-1110.

Chi, M.C., and C.S. Li (2006). Analysis of bioaerosols from chicken houses by culture and non-culture method. Aerosol Sci. Technol. 40(12): 10711079.

Chi, M.C., and C.S. Li (2007). Fluorochrome in monitoring atmospheric bioaerosols and correlations with meteorological factors and air pollutants. Aerosol Sci. Technol. 41(7): 672678.

Chien, Y.C., C.J. Chen, T.H. Lin, S.H. Chen, and Y.C. Chien (2011). Characteristics of microbial aerosols released from chicken and swine faeces. J Air Waste Manag. Assoc. 61(8): 882889.

Chinivasagam, H.N., T. Tran, L. Maddock,A. Gale, and P.J. Blackall (2009). Mechanically ventilated broiler sheds: a possible source of aerosolized Salmonella, Campylobacter, and Escherichia coli. Appl. Environ. Microbiol. 75(23): 74177425.

Crook, B., A. Easterbrook, and S. Stagg (2008). Exposure to dust and bioaerosols in poultry farming. Summary of observations and data. Prepared by the Health and Safety Laboratory for the Health and Safety Executive.

De Lucca, A.J. (2007). Harmful fungi in both agriculture and medicine. Revistaiberoamericana de micología, 24(1): 3.

De Roy, K., L. Clement, O. Thas, Y. Wang, and N. Boon (2012). Flow cytometry for fast microbial community fingerprinting. Water Res.46(3): 907-919.

Donderski, W., M. Walczak, and M. Pietrzak (2005). Microbiological contamination of air within the city of Torun. Pol. J Environ. Stud. 14(2): 223230.

Donham, K.J., D. Cumro, S.J. Reynolds, and J.A. Merchant (2000). Dose-Response Relationships between Occupational Aerosol Exposures and Cross-Shift Declines of Lung Function in Poultry Workers: Recommendations for Exposure Limits. J Occup. Environ. Med. 42(3): 260-269.

Douwes, J., P. Thorne, N. Pearce, and D. Heederik (2003). Bioaerosol health effects and exposure assessment: progress and prospects. Anna. Occup. Hyg. 47(3): 187-200. 
Gigli, A.C.S., M.S. Baracho, I.A. Nääs, R.A. Silva, R. Zago, and F.P. Dall'Anese (2005). Diagnosis and evaluation of fungi presence in the air of two different ventilation sytems for broiler houses. Braz. J. Poult. Sci, 7(4): 205-208.

GOP (Government of Pakistan) Economic Survey of Pakistan, Ministry of finance, Government of Pakistan. 2014

Hussain, J., I. Rabbani, S. Aslam, and H.A. Ahmad (2015). An overview of poultry industry in Pakistan. World's Poult. Sci. J. 71(4): 689-700.

Jerez, S.B., Y. Cheng, and J. Bray (2014). Exposure of workers to dust and bioaerosol on a poultry farm. J. Appl. Poult. Res. 23(1): 7-14.

Jo, W.K., and J.H. Kang (2005). Exposure levels of airborne bacteria and fungi in Korean swine and poultry sheds. Arch. Environ. Occup. Health. 60(3): 140-146.

Just, N., C. Duchaine, and B. Singh (2009). An aerobiological perspective of dust in cagehoused and floor-housed poultry operations. J. Occup. Med. Toxicol. 4(1): 13.

Just, N.A., V. Létourneau, S.P. Kirychuk, B. Singh, and C. Duchaine (2011). Potentially pathogenic bacteria and antimicrobial resistance in bioaerosols from cage-housed and floor-housed poultry operations. Ann. Occup. Hyg. 56(4): 440-449.

Liang, L., G. Engling, Y. Cheng, F. Duan, Z. Du, and K. He (2013).Rapid detection and quantification of fungal spores in the urban atmosphere by flow cytometry.J. Aerosol Sci.66: 179-186.

Lonc, E., and K. Plewa (2011). Comparison of indoor and outdoor bioaerosols in poultry farming. In Advanced Topics in Environmental Health and Air Pollution Case Studies. InTech.

Matkovic, K., M. Vucemilo,I. Stokovic, I., R. Simic, D. Marusic, B. Vinkovic, and S. Matkovic (2013). Concentrations of airborne bacteria and fungi in a livestock building with caged laying hens. Vet arhiv. 83: 413-424.

Muller, S., and G. Nebe-von-Caron (2010). Functional single-cell analyses: flow cytometry and cell sorting of microbial populations and communities. FEMS Microbio. Reviews. 34(4): 554-587.

Nimmermark, S., V. Lund, G. Gustafsson, and W. Eduard (2009). Ammonia, dust and bacteria in welfareoriented systems for laying hens. Ann. Agri. Environ. Med. 16(1): 103-113.

Nonnenmann, M.W., B. Bextine, S.E. Dowd, K. Gilmore, and J.L.Levin (2010). Culture-independent characterization of bacteria and fungi in a poultry bioaerosol using pyrosequencing: a new approach. J. Occup. Environ. Hyg. 7(12): 693699.
Oppliger, A., N. Charriere, P.O.Droz, and T. Rinsoz (2008). Exposure to bioaerosols in poultry houses at different stages of fattening; use of real-time PCR for airborne bacterial quantification. Ann. Occup. Hyg. 52(5): 405412.

Peccia, J., and M. Hernandez (2006). Incorporating polymerase chain reaction-based identification, population characterization, and quantification of microorganisms into aerosol science: a review. Atmos. Environ. 40(21): 3941-3961.

Radon, K., C. Weber, M. Iversen, B. Danuser, S. Pedersen, and D. Nowak (2001). Exposure assessment and lung function in pig and poultry farmers. Occup. Environ. Med. 58(6): 405-410.

Rinsoz, T., P. Duquenne, G.Greff-Mirguet, and A. Oppliger (2008). Application of real-time PCR for total airborne bacterial assessment: Comparison with epifluorescence microscopy and culture-dependent methods. Atm. Environ. 42(28): 6767-6774.

Romanowska-Słomka, I., and J. Mirosławski (2009). Biological hazards in an industrial poultry farmresearch results. BezpieczeństwoPracy, 7: 16-19.

Roque, K., G.D. Lim, J.H. Jo, K.M. Shin, E.S. Song, R. Gautam, and Y. Heo (2016). Epizootiological characteristics of viable bacteria and fungi in indoor air from porcine, chicken, or bovine husbandry confinement buildings. J. Vet. Sci. 17(4): 531-538.

Rubbens, P., R. Props, N. Boon, and W. Waegeman (2017). Flow cytometric single-cell identification of populations in synthetic bacterial communities. PloS one. 12(1): e0169754.

Schulz, J., J. Hartung, J. Seedorf, and L.C. Formosa (2004). Staphylococci as an indicator for bacterial emissions from a broiler house. In Proceeedings of In Between Congress of The International Society for Animal Hygiene, Animal production in Europe: The way forward in a changing world, Sant-Maolo, France 1: 75 78).

Skora, J., K. Matusiak, P. Wojewódzki, A. Nowak, M. Sulyok, A. Ligocka, and B. Gutarowska (2016). Evaluation of microbiological and chemical contaminants in poultry farms. Int. J. Environ. Res. public health. 13(2): 192.

Soliman, E.S., M.A. Sobeih, M. Hussein, H. AbdelLatiff, and A. Moneim (2009). Seasonal epidemiological surveillance on bacterial and fungal pathogens in broiler farms in Egypt. Int. J. Poult. Sci. 8(8): 720-727.

Viegas, C., S. Viegas, A. Monteiro, E. Carolino, R. Sabino, and C. Veríssimo (2012). Comparison 
of indoor and outdoor fungi and particles in poultry units.

Vucemilo, M., K. Matkovic, B. Vinkovic, J. Macan, V.M. Varnai, L.J. Prester, and T.Orct (2008). Effect of microclimate on the airborne dust and endotoxin concentration in a broiler house. Czech J. Anim. Sci. 53(2): 83-9.

Wang, Y., F. Hammes, K. De Roy, W. Verstraete, and N. Boon (2010). Past, present and future applications of flow cytometry in aquatic microbiology.Trends Biotechnol. 28(8): 416424.

Whitton, R., S. Fane, P. Jarvis, M. Tupper, M. Raffin, F. Coulon, and A. Nocker (2018). Flow cytometrybased evaluation of the bacterial removal efficiency of a blackwater reuse treatment plant and the microbiological changes in the associated non-potable distribution network. Sci. Total Environ. 645: 1620-1629.

Wojcik, A., L. Chorazy, T. Mituniewicz, D. Witkowska, K. Iwańczuk-Czernik, and J. Sowinska (2010). Microbial air contamination in poultry houses in the summer and winter. Pol. J. Environ. Studies. 19(5): 1045-1050.

Yoo, K., T.K. Lee, E.J. Choi, J. Yang, S.K. Shukla, S.I. Hwang, and J. Park (2017). Molecular approaches for the detection and monitoring of microbial communities in bioaerosols: A review. J. Environ. Sci. 51: 234-247. 